Agenda, Volume 2, Number 4, 1995, pages 423-431

\title{
Guaranteeing Access to Essential Infrastructure
}

\author{
Stephen P. King
}

$\mathrm{T}$ THE Australian federal government's Competition Policy Reform Act 1995 (CPRA), together with matching State legislation, represents the culmination of a reform process that began with the Hilmer Committee report. ${ }^{1}$ At the heart of this Act are rules designed to administer third-party access to essential infrastructure facilities such as 'electricity transmission grids, telecommunications networks, rail tracks, major pipelines, ports and airports' (Hilmer et al., 1993:240). These rules aim to expand competition in upstream and downstream markets by forcing the owners of key facilities to allow potential competitors access to these facilities, which, otherwise, would give their owners unassailable monopoly power. Access is already required in telecommunications; Optus has negotiated an agreement for access to Telstra's (Telecom Australia's) network. But the aim of the CPRA is to make such agreements the norm rather than the exception.

The Act includes a number of principles that the relevant minister and regulatory authorities must observe both when declaring a facility liable for access and when determining an access agreement. $\mathbf{A}$ facility owner may be forced to provide access when 'access (or increased access) to the service would promote competition in at least one market', when it is not economical 'for anyone to develop another facility to provide the service', and when 'the facility is of national significance' (44G.2.a, b, c).

The Act assumes that the parties to any access agreement will, in the first instance, negotiate the specifics of such an agreement between themselves. However, if agreement cannot be reaclied the parties must go to arbitration before the Australian Competition and Consumer Commission. The commission will then make a determination based upon a number of guiding principles and specific limitations (44X and $44 \mathrm{~W}$ ). The aim of this process is to achieve access without infringing on the legitimate rights of facility owners and with $\dot{a}$ minimum of bureaucratic and regulatory intervention.

\footnotetext{
'Formally known as the Independent Committee of Inquiry inlo National Competition Policy (see Hilmer et al., 1993). This article deals only with the CPRA as, at the time of writing, details of the relevant $S$ tate bills are generally not available.
}

Stephen King is in the Economics Program in the Research School of Social Sciences at The Australian National University. 


\section{Preliminary Issues}

Why is any of this legislative framework necessary? The underlying principle, drawn from the Hilmer report, is that industries such as electricity and gas contain core infrastructure facilities which are 'natural monopolies'. The services provided by these facilities are an essential input into the production of some final good(s) or service(s), so that, in the absence of access arrangements, these facilities endow their owners with monopoly power. In Australia, many of the relevant facilities are owned by State governments and the end markets are monopolised by State-owned utilities. Access rules are designed to break down this monopoly power and to introduce competition into the end markets by making available the essential input controlled by the utilities.

Three key preliminary questions should precede any enforced access regime. What is the 'end market' that requires access to ensure competition? Is the relevant facility really essential for that competition? And what are the costs of mandated access?

Defining the end market. How is the correct end market to be determined? Consider, for example, a gas transmission pipeline that leads to Sydney. Does this pipeline service a Sydney gas market, or are gas sales merely one part of a larger Sydney market for energy sources and fuels? If the market is defined as the former and if the pipeline is the only economically feasible way to ship gas to Sydney, then access to that pipeline is clearly crucial for any firm wishing to compete in the Sydney gas market. However, if the relevant market is that for energy sources and fuels, so that gas is merely one of a number of competing fuel sources, access may not even be important, far less essential.

This question is not merely a matter of semantics, but is crucial to both the implementation and economic implications of the CPRA. Market definition and the interpretation of 'promote competition in a market' will be the first legal hurdles for any access declaration. These issues will determine whether access, with the accompanying legislative constraints, is required. Market definition will establish the future regulatory path of the relevant industry. Choosing the wrong path may have significant efficiency consequences. For example, Teece (1990) compares American and German natural gas regulation. Whereas the US has relied on significant and often misdirected regulatory intervention, Germany has relied on interfuel competition to control the gas industry. Teece finds that Germany has consistently outperformed the US in terms of both price and utilisation of pipeline capacity. Focusing on an incorrect or irrelevant end market can lead either to the maintẹnance of monopoly power or to costly intervention where none is needed.

But is it essentialP The Hilmer report cites competition as the rationale for access regulation. Competition cannot be left to normal market pressures because of a natural monopoly problem. 'Like other monopolists ... the owner of the facility is able to use its monopoly position to charge higher prices and derive monopoly profits at the expense of consumers and economic efficiency' (Hilmer et al., 
1993:241). The CPRA captures the 'natural monopoly' feature of an access facility by requiring that the National Competition Council and the relevant minister can declare a facility only if 'it would be uneconomical for anyone to develop another facility to provide the service' (44G.2.b and 44H.4.b).

The term 'natural monopoly' refers to an industry where the cost-minimising production technology requires that, at all relevant levels of demand, it is more efficient if output(s) are supplied by one producer than by more than one producer. 'All relevant levels of demand' means all quantities of the product(s) that would be purchased at a price or prices that are at least equal to marginal cost. 'More efficient' means that the total cost of production of the product(s) is minimised with a single producer for all possible combinations of the relevant quantities. It immediately follows that what is or is not a natural monopoly will change with technical progress and with changes in the nature of demand, particularly the expansion of demand over time. A facility that is a natural monopoly today need not be one tomorrow.

Little attempt seems to have been made to determine which, if any, of the facilities mentioned in the Hilmer report are natural monopolies. For example, while I am quite happy to accept that domestic gas distribution is likely to embody a natural monopoly teclmology (I am also quite ready for someone to show me data that proves that this is incorrect), it is far from obvious that gas transmission involves a natural monopoly technology. Ellig and Giberson consider intrastate gas transmission in Texas and find that 'most firms operate at substantial decreasing returns to scale' (1993:79). Similarly, until relatively recently long-distance telephone communications was viewed as 'obviously' a natural monopoly. However, anyone claiming that Melbourne-Sydney long-distance telephony is a natural monopoly today is likely to be greeted with slurieks of laughter.

If the facilities to be regulated by the CPRA do not exhibit natural monopoly characteristics, it is far from clear that third-party access is desirable even if an 'essential' input for an end market is provided. But the preliminary work to determine which facilities may warrail access regulation has not been carried out. Without this work, the relevant authorities have no basis for judging whether a facility is or is not a natural monopoly or whether it would be economical to develop an alternative, competing facility.

The costs of access. Finally, there has been litule discussion of the direct and indirect costs of third-party access. These costs will, in part, depend upon the regulatory regime and the infrastructure used to support this regime. The relevant federal and State regulatory bodies will not be free. The requirements that these regulators place upon declared facilities may involve substantial costs of negotiation, arbitration and compliance. As well, allowing access may incur substantial direct costs related to the loss of economies of scope. For example, Kaserman and Mayo (1991) show that the costs arising from the loss of vertical economies in separating electricity generation from distribution through arms-length contracts may be significant. 
Invoking a 'light handed' regulatory regime will not necessarily reduce these costs and may, in fact, exacerbate the problem. For example, in New Zealand there is no statutory requirement for the owner of the existing telecommunications network, Telecom New Zealand, to allow interconnection access to a competitor. Access issues were deliberately left for the courts to interpret under section 36 of $\mathrm{New}$ Zealand's Commerce Act 1986, which deals with abuse of a dominant position. As a result, the issue of interconnection between the local network that is being established by Clear Communications and the existing network of Telecom New Zealand led to a long-running court battle that culminated in a ruling by the Privy Council (see Ross, 1995). This protracted battle has involved significant direct costs to all participants and also a substantial delay in interconnection. Similarly, the use of a negotiated interconnection regime for telecommunications in the UK resulted in a four-year delay following the licensing of Mercury in 1982. Eventually, the Director General of Telecommunications liad to step in and rule on the conditions for interconnection between Mercury and BT (Armstrong et al., 1994).

The potential costs of access have not been considered in Australia. While it is hoped that the CPRA will result in swifty negotiated agreements, it may become mired in forced arbitration, appeals and disputes on points of law. The fundamental question of whether the potential gains to competition are worth the costs remains to be answered.

\section{Negotiated Access Regimes}

The CPRA envisages, in the first instance, that the facility owner and the parties requiring access will negotiate mutually agrecable conditions for access. This is in line with the preferred approach outhined in the Hilmer report.

At first glance, access agreements that are directly negotiated between the facility owner and the firm requiring access have significant economic merit. Despite the possibility of 'game playing' between these parties wlien negotiating agreements, there are good reasons to believe that such bargaining would be reasonably efficient. It is in no party's interest to bargain to an outcome that results in a loss to one party that is not matched by a gain to the other. While the access provider may have a significant incentive to stall negotiations if it is also operating in the end market, negotiated access with forced arbitration if no agreement is reached would appear to provide a path to sensible access agreements.

Yet access agreements that are eflicient for both the provider and purchaser of access services need not be economically eflicient: quite the contrary. The incentives in access negotiations will be to maximise the benefits that can be divided between the access provider and those lirms using access as an input to a final product. If the access provider has monopoly control over an essential input, then the way to maximise these benefits is to use the access regime to ensure monopoly pricing in the end markets.

To see this, consider that the access facility owner does not compete in the final market. It is then desirable for the access provider and one of the third parties wishing to buy access to sign a contract that ensures that they share the maximum 
monopoly rents achievable in the final market. For example, they could set a simple two-part tariff involving a per unit price equal to the (short-run) marginal cost of the access services. The firm buying access will then set the overall profit maximising price in the final market, and the fixed component of the tariff can be used to share the monopoly profits. So long as this fixed component is equal to at least one-half of the monopoly rents, the access facility owner can offer an identical contract to all potential access purchasers, sale in the knowledge that it would never pay more than one firm to accept such a contract.

An alternative contract may be oflered by the lacility owner if it believes that there are likely to be numerous potential access purchasers who, given the opportunity, would compete vigorously in the end market. In such a situation, the access provider will wish to encourage competition in the end market so that the price in this market is driven down to cost. This cost will, however, include an inflated uniform price for access. By controlling the access price and encouraging competition, the access provider is able simultaneously to control the price in the final market and to retain any profits generated at this price. Again, access would be offered on a non-discriminatory basis. Further, the regime would appear to be highly successful in that it would result in intense competition in the final market.

These examples suggest that there will be strong pressure under negotiated access price agreements for monopoly pricing in the linal goods market. This situation does not change significantly when the access provider also operates in the final goods market. In the first example, the access provider can gain monopoly profits by either leaving the final market to a single purchaser of access or by 'sharing' the final market with one or a small number of other firms who act as a cartel. In this latter case the access provider could gain the prolits through the access regime and also enforce the cartel by 'punishing' any deviant lirm through its power over access. In the second example, the access provider will be able to use its own presence in the end market to price aggressively and ensure that this market operates in a highly competitive fashion.

\section{Investment and Access}

A determination under the CPRA can require an access provider to extend its facility (44V.2.d), subject to that owner not bearing any of the costs of the extension (including on-going maintenance costs) (44W.1.e). Although such provisions appear reasonable when considering extensions that are necessary for access (such as an interconnection switch in telecommunications), it is far from obvious that these provisions will create the correct incentives for the facility owner to choose a socially optimal capacity level. Depending upon the specific access agreements and determinations that it faces, a facility owner will wish to manipulate capacity over time to maximise its profits.

As an example, consider that a facility owner faces an access regime that maximises economic efficiency given current capacily. If demand alters in a reasonably stable cycle over time, such a regime will include access prices set equal to short-run marginal cost when demand is low and the lacility las excess capacity and rationing 
demand by price when the facility is operating at capacity. This simple peak-load pricing scheme ensures that the facility is used optimally off-peak and that, in the peak period, when demand has to be rationed, available access goes to the highest valued users.

Under such a pricing scheme, it is socially desirable for capacity to be expanded whenever the price in the peak period (weighted by the proportion of the cycle in which peak demand occurs) exceeds the marginal cost of such expansion (the 'longrun' marginal cost). However, the incentives that face the facility owner are significantly different. By constraining capacity, the owner of the facility can exert some monopoly power over peak demand. Expanding capacity undercuts this monopoly power by increasing the supply of the scarce resource controlled by the facility owner. In fact, from the facility owner's viewpoint, desirable capacity is not determined by the socially optimal rule of (weighted) peak-price equalling long-run marginal cost, but rather by the profit-maximising rule that marginal revenue at the peak equals this marginal cost. If price rationing is used for peak demand, the facility owner will generally wish to maintain or reduce capacity when it is socially desirable to expand.

This example clearly depends upon the specilic rule used to price access. But similar problems will usually arise with any access arrangements. Whenever price is used to ration access, it will be in the interest of the facility owner to exert monopoly power over that price by limiting capacily. Conversely, if access prices are determined to give the facility owner a 'reasonable' or 'commercial' rate of return on the capital value of its facility, with peak access rationed by some non-price means, then the facility owner will wish to manipulate capacity to maximise its profits subject to the regulated rate. If the regulatory authorities set a rate that is below the true cost of capital, it will pay the access provider to allow its facilities to run down. Conversely, if the allowed rate of return is above the true cost of capital, the facility owner will want to expand capacity above the level that is socially optimal so as to maximise the capital on which its allowable returns are based. ${ }^{3}$ In the simple case considered here, if the access price was set equal to long-run marginal cost and the regulatory authorities required that the access facility owner serve all customers at that price, the conflict between private and social incentives to expand capacity would disappear. If the (weighted) price that would ration peak demand exceeded long-run marginal cost, the facility owner would be forced to expand capacity to satisfy the requirement to provide access. However, it would never pay the facility owner to over-expand capacity as this would simply lead to idle capital for which it receives no return.

\footnotetext{
${ }^{2}$ For a formal discussion of peak-load pricing, see Mitchell and Vogelsang (1991). Also see $\mathrm{Ng}$ (1987) for a discussion of socially optimal capacity expansion over time for lacilities with lumpy costs. In the discussion here we consider the simple case where there is only one, well-defined peak period.

$\mathbf{3}$

That rate-of-return regulation can lead to excessive capitalisation of production is well known and referred to as the 'Averch-Johnson eflect'. See Train (1991).
} 
There are, however, two reasons why such pricing is impractical and undesirable. First, long-run marginal cost pricing may lead to efficient capacity but it leads to inefficient use of that capacity by setting the price too high in off-peak periods. Second, it is unlikely that the regulatory authorities will know the value of long-run marginal cost with any accuracy and the access facility owner will have little incentive to provide this information correctly. As a consequence it is unlikely that the authorities could set price equal to long-run marginal cost. Further, such regulatory intervention is clearly contrary to the intention of the CPRA with its reliance on negotiated access agreements.

A similar problem arises with both the building of new facilities and the technology embodied in such facilities. The regulatory regime will affect these choices in ways that may be inimical to economic efficiency. For example, the CPRA requires that access determinations not prevent 'an existing user obtaining a sufficient amount of the service to be able to meet the user's reasonably anticipated requirements' (44W.1.a). This provision will affect the choice of a provider when building a new facility. If the facility is likely to last for, say, 20 years, it may be economically desirable to build a facility with significant excess capacity today in expectation of increased final market demand over time. However, if excess capacity can be utilised by potential final-market competitors in the years immediately following construction, then this will lower the facility owner's prolits from participating in the end market even if access to the facility includes a 'commercial rate of return'. As a consequence, the investor may prefer to build a facility which is smaller than would otherwise be desirable so as to limit short-term excess capacity, and also to use as much of the available capacity as possible even if such use was completely wasteful. For example, it may pay a gas company to build a pipeline that is likely to reach capacity earlier than otherwise desirable, and in the short term to use any otherwise excess capacity to ship gas that is simply burnt off at the other end of the pipe and not sold in the final market.

The ability of potential access purchasers to by-pass facilities that have been declared under the CPRA may place some competitive pressure on the access provider. By-pass involves an end-market seller or an cnd-market customer investing in his own facilities to avoid using the dedicated access facilities. For example, bypass in telecommunications can involve a large corporate customer setting up its own internal switching facilities and using designated lines to connect its major corporate offices in order to avoid using the public long-distance network, or to directly connect to a long-distance company in order to avoid using a local exchange carrier. (For an extensive discussion of by-pass, see Kahn, 1988.)

The ability to by-pass places a competitive burden on the facility owner that would otherwise not exist. However, it should be remembered that, under the CPRA, a facility will be subject to an access regime only if it is uneconomic for competitive facilities to be developed. Thus, in the context of the CPRA, by-pass will necessarily be economically wasteful: otherwise, the relevant facility should not be subject to declaration. 
Inefficient by-pass will occur if the (total) price being charged for access exceeds the stand-alone cost of building an alternative facility. Thus, stand-alone costs place an upper bound on the price that the facility owner can charge for access without inducing by-pass. The discipline imposed on the facility owner by potential by-pass will, however, differ greatly depending upon the specific input being purchased, the number of third-parties requiring access and the relative use of the facility by the owner and other parties. In general, with a policy of 'open access', whereby the facility provider is able to set any non-discriminatory price for access that he desires, the possibility of by-pass is likely to impose only a small degree of restraint on the facility owner.

\section{Conclusion}

The Competition Policy Reform Act 1995 is based on good intentions. When dealing with third-party access, the Act retains the spirit of the Hilmer report and provides a long list of considerations to protect the interests of the access providers and the access purchasers. However, the Act ignores many of the serious practical problems that will arise in implementing any access regime. It brushes aside three important preliminary considerations of any access regime. The issues of market determination and whether or not an altemative lacility can be 'economically' developed are left as one-line points to be considered in declaring a facility. The issue of access costs not explicitly related to access facilities, such as contracting costs and loss of scale economies, is not considered at all.

The emphasis in both the Hilmer report and the CPRA on negotiated access essentially disenfranchises the most important party to any access considerations: the final consumers. The interests of these consumers are reflected in the requirements that access must promote competition and that an access determination must take 'the public interest' into account (44X.1.b). However, the emphasis on negotiated access arrangements means that those parties with the least interest in competition and consumer welfare liave the greatest say in any access arrangements.

Finally, the Act does not resolve the important conllict between static and dynamic economic efficiency that will necessarily arise with any access regime. An illfounded access regime may lead to over- or under-investment in the relevant facilities and may potentially make consumers worse off than under monopoly provision even if it has the cosmetic effect of raising the number of firms 'competing' in the final market.

It is far from clear that the intentions of the Competition Policy Reform Act will be realised in practice. If State legislation is mirrored on this federal Act, the hopes raised by the Hilmer report and the subsequent analyses in the press and elsewhere may be dashed. 


\section{References}

Armstrong, M., S. Cowan \& J. Vickers (1994), Regulatory Refoum: Economic Analysis and the British Experience, MTT Press, Cumbridge MA.

Ellig, J. \& M. Giberson (1993), 'Scale, Scope and Regulation in the Texas Gas Transmission Industry', Journal of Regulatory Economics 5: 79-90.

Hilmer, F., M. Rayner \& G. Tayerell (1993), National Competition Policy: Report by the Independent Committee of Inquiry, AGPS, Canbent.

Kahn, A. (1988), The Economics of Regulation, MIT Press, Cambriclge MA.

Kaserman, D. \& J. Mayo (1991), 'The Measuremcnt ol Vertical Fconomies and the Efficient Structure of the Electric Utility Business', Journal of Industrial Economics 39: 483-502.

Mitchell, B. \& 1. Vogelsang (1991), Telecommunications Priciug. Theory and Practice, Cambridge University Press, Cambridge.

Ng, Y-K. (1987), 'Equity, Ffliciency and Financial Viability: Public-Uuility Pricing with Special Reference to Water Supply', Australian Economic Review, 3rd. quauter: 21-35.

Ross, M. (1995), 'New Zealand's Experiment in Pricing Access to Essential Facilities', Agenda 2(3): $366-70$.

Teece, D. (1990), 'Stucture and Organization of the Natural Gas Industry: Dillerences between the United States and the Federal Republic of Germany and Implications for Carrier Status Pipelines', The Energy Journal 11: 1-35.

Train, K. (1991), Optimal Regulation, MIT Press, Cambridge MA.

This article is based on a discussion paper that the author prepared for the NSW Government Pricing Tribunal. However, the views expressed are those of the author not necessarily those of the Government Pricing Tribunal. 